IOSR Journal of Pharmacy

e-ISSN: 2250-3013, p-ISSN: 2319-4219, www.iosrphr.org

Vol. 2, Issue 6, Nov-Dec. 2012, PP. 08-13

\title{
In vitro cytotoxic study for pure extracellular toxin complex from Klebsiella pneumoniae $\mathrm{K8}$
}

\author{
${ }^{1}$ Essam F. Al-Jumaily, ${ }^{1}$ Mohammed S. Mohammed, ${ }^{2}$ Nahi Y. Yaseen \\ ${ }^{I}$ Biotechnology Deparment, Genetic Engineering and Biotechnology Institute for postgraduate studies, \\ Baghdad University, Baghdad, Iraq \\ ${ }^{2}$ Iraqi Centre of Cancer Research and Medical Genetics, Al-Mustansyria University
}

\begin{abstract}
The aim of this study to examine the cytotoxic effect of pure extracellular toxin complex of K.pneumoniae $\mathrm{K8}$ on Rat embryo fibroblast cell line (REF-11). The monolayer cells were exposed to serial dilution of that purified toxin and incubated at $37^{\circ} \mathrm{C}$ with $5 \%$ of $\mathrm{CO}_{2}$ for three days . REF-11 cells were then examined after 24,48 , and 72 hours. The results shows that the pure extracellular toxin have biological effect on REF-cells by changed their morphology from spindle shape to irregular shape and appeared to be cytotoxic for REF -cells by many vacuoles have been showed inside REF-cells and finally the cells appeared necrotized.
\end{abstract}

Keywords: - K.pneumoniae, rat embryo fibroblast (REF-11), Extracellular Toxin Complex (ETC)

\section{INTRODUCTION}

Klebsiella pneumoniae is an opportunistic pathogen frequently causes nosocomial infections, mainly in immunocompromised patients, and its infections range from mild urinary tract infections to severe bacteremia and pneumonia with high rate of mortality and morbidity [1].

The endotoxin molecule consists of three different parts: a non- polar lipid component (Lipid A ), a core of oligosaccharide and heteropolysaccharides, Surface O- antigen [2,3]. Lipid A is the most conservative part of LPS and is responsible for the toxicity. Lipid A or endotoxin have particular influence on monocytes and macrophages. Activated cells release mediators, such as tumor necrosis factor (TNF), interleukins (IL), colony stimulating factor (CSF) $[4,5,6,7,8]$.

Straus [9] described the production of an extracellula toxic complex (ETC) that appeared to be responsible for lethality and the extensive lung pathology produced by $K$. pneumoniae in animal models. Straus et al I, [10] reported that (ETC) was made of 63\% CPS, 30\% LPS, and 7\% protein. Saponification studies demonstrated that the toxicity of the (ETC ) was associated with the LPS, but the LPS alone was decidedly less toxic than the entire complex. Since the ETC from only one strain of $K$. pneumoniae was employed, and examined additional strains for the production of that complex , that all strains of K.pneumoniae had capable of producing the ETC, but if they do not possess sufficient cell- associated capsule, they are cleared by phagocytic mechanisms of the animal and never had the opportunity to release extracellular toxic product. Research on the pathogenesis of experimental infections with K. pneumoniae has shown the Capsular polysaccharide (CPS) to be a prime factor in virulence [11] .

\section{MATERIALS AND METHODS}

\section{Bacterial isolate :}

Ten isolates of Klebsiella pneumoniae were employed in this study obtained from the Central Public Health Laboratory / Ministry of Health , and AL - Kindy Teaching Hospital Laboratory /Baghdad. The isolates were collected from sputum of patients suffered from pneumonia, during the period of November 2004- March 2005. According to standard microbiological and biochemical techniques, and the use of ( API 20E- System), all isolates were considered to be $K$. pneumoniae .Test for the ability to produced toxins was performed on all isolates, then Isolate No.8 was selected in this study for production and purification of toxin . Purified Extracellular Toxin (ETS) from local isolate Klebsiella pneumoniae K8 was prepared by Mohammed [12].

\section{Cytotoxic Effects of Extracellular toxin complex on Cell Line in vitro}

The invitro methods was used to investigate the effect of pure extra cellular toxin on Rat Embryo Fibroblast (REF-11) was obtained from Iraqi Center for Cancer and Medical Genetics Research. The cells were cultured on RPMI-1640 medium supplemented with $20 \%$ fetal bovine serum (FBS), and incubated at $37^{\circ} \mathrm{C}$ with $5 \% \mathrm{CO}_{2}$. 


\section{Purified Extracellular toxin complex dilutions}

One $\mathrm{ml}$ of purified toxin ( $200 \mathrm{mg} / \mathrm{ml}$ ) was sterilized by $(0.22 \mu \mathrm{m})$ millipore filter membrane, and prepare six sterilized tubes contain $1 \mathrm{ml}$ of sterilized (RPMI-1640) medium without fetal bovine serum (FBS), added to the first tube $1 \mathrm{ml}$ of toxin mixed well and then transferred $1 \mathrm{ml}$ to the second tube, continue this process to the sixth tube. Finally the two fold serial dilutions of each sample became as: $1 / 2 \quad 1 / 4 \quad 1 / 8 \quad 1 / 16 \quad 1 / 32 \quad 1 / 64$ and control (contain RMPI-1940 medium only).

\section{Cell viability assay}

It is also called a cell growth inhibition assay. In this assay, the three types of cell lines were treated with pure lignan extract and standard concentrations ranging from $50 \square \mathrm{g} / \mathrm{ml}$ to $100 \mu \mathrm{g} / \mathrm{ml}$, at the same time the lines were exposed to methotrexate drug in concentrations ranging from $0.05 \mu \mathrm{g} / \mathrm{ml}$ to $0.4 \mu \mathrm{g} / \mathrm{ml}$ using a microtiteration plate (96 wells) cell culture technique. The protocol assay, which included the following steps [13] :

(a) Seeding : The tryptinized and suspended cells were seeded in a microtiter plate by taking $0.2 \mathrm{ml}$ cell suspension into each well that might contain $\left(10^{4}-10^{5}\right)$ cells/well, growth medium used for seeding

(b) Incubation: All plates were incubated in $\mathrm{CO}_{2}$ incubator at $37^{\circ} \mathrm{C}$ for full cells attachment.

(c) The treatment ( or cells exposure): Using the maintenance medium (serum free medium) as a negative control and serum free medium with $0.1 \%$ DMSO as positive control, the microtiter plates after cells attachment were exposed to serial dilutions of pure lignan and methotrexate in the concentrations rang mentioned before .

The exposure times were (24,48 and 72$)$ hours. Each plate was designed to contain three replications of each concentration and 12 wells for negative control and 12 wells for positive control.

(d) Recovering times and reading the results: At the end of the exposure times the medium was decanted off, the cells in the wells were gently washed by the addition of sterile PBS twice, finally $50 \mu 1$ of crystal violate stain was added to the wells and the plates were incubated for 30 minutes at $37^{\circ} \mathrm{C}$, then the plates were washed gently with distilled water and left to dry .

The plates of different cell culture at the end of the assay were examined by ELISA reader at $492 \mathrm{~nm}$ transmitting wave length .

Only viable cells were able to take the stain, the dead cells were not. The proliferation rate was measured according to [12] and as follows:

roliferation rate $\%=$

While the inhibitor rate was measured according to [14] as follows:

Inhibitor rate $\%=$

$$
\text { x } 100
$$

\footnotetext{
Abs $=$ Absorance

The -ve results referred to the inhibition rate \%

While the +ve results referred to proliferation rate $\%$

All values were analyzed statically
}

\section{Toxin assay in vitro}

Under aseptic conditions, REF-cells which was cultured in PRM1-1640 were examined under the inverted microscope to be sure that the confluent monolayer was formed, and no bacterial or fungal contamination in that cultures. Then the following steps were done

Removed medium by pouring it off aseptically. Rinsed the monolayer with PBS solution. REF cells were passaged by trypsin versene .Poured off the trypsin versene and added to the cells $20 \mathrm{ml}$ of serum free medium.Transferred $0.2 \mathrm{ml}$ of cell suspension into microtiter plates of 96 wells. Each wells was seeded with $3 \times 10^{3}$ cells $/ \mathrm{ml}$ incubated the microplate at $37^{\circ} \mathrm{C}$ supplemented with $5 \% \mathrm{CO} 2$ for $(12-18)$ hours the plate was examined under inverted microscope to be sure that the cells in each wells was attached to the button of the well. Removed the medium by pouring it off aseptically added $0.2 \mathrm{ml}$ of toxin samples and incubated at $37^{\circ} \mathrm{C}$ ,with $5 \% \mathrm{CO}_{2}$ for $24,48.72$ hours. After the finishing of exposure time ,the plate was added to it $50 \mathrm{ul}$ of crystal violet and the plate was returned to the incubator again, to incubated for 2 hours. Then the plate was washed with (PBS). 
Microscopical examination of (REF-Cells)

Rat embryo fibroblast cells (REF-11) were examined under the inverted microscope and photographe were recorded, the effect of the purified toxin of Klebsiella pneumoniae $\mathrm{K} 8 \quad$ ( chosen isolate ) on cultured cells was investigated.

\section{RESULTS AND DISCUSSION}

Rat embryo fibroblast cells ( REF -11 ) were cultured in RPMI 1640 medium. Figure (1) showing the normal morphology of REF-cells after 48 hours.

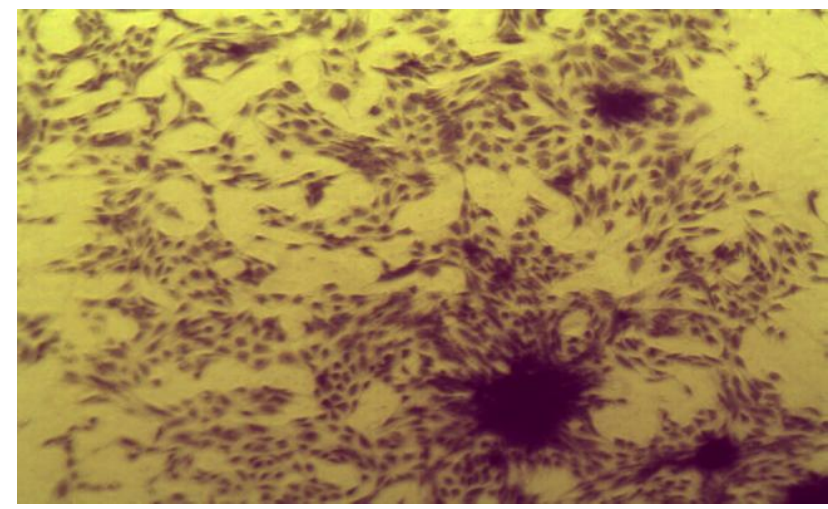

Figure (1): Rat embryo fibroblast cells (REF-11) seeded in 96-well plate and cultured in RPMI-1640 medium .cells are untreated with purified toxin of K.pneumoniae $\mathrm{K8}$, Magnification is $4 \mathrm{X}$ and used as (control).

After 72 hours the monolayer cells of REF-11 was examined under inverted microscope as in figure (2).

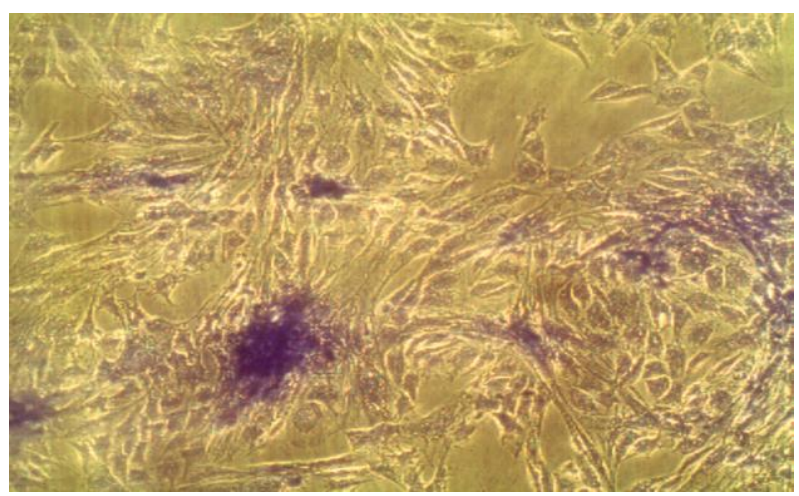

Figure (2): Rat embryo fibroblast cells (REF-11) seeded in 96-well plate and cultured in RPMI-1640 medium for 72 hours showing the normal shape of cells .Magnification is 40X.in inverted microscope.

Endotoxin is an amphiphathic membrane produced by gram negative bacteria. It might interferes with the membrane structure and function in other cells. The interaction of endotoxin with cell membranes may be apparent as morphological changes and increased organelles, large vacuoles in the cytoplasm, and sever membrane damage as showed in figures 3, 4,5,6 respectively. 
Figure (3): REF-11 cell treated with Purified toxin of K.pneumoniae K8 isolate
Figure (4): REF-cells treated with purified toxin of K.pneumoniae $\mathrm{K8}$,showing morphological change
Figure ( 5) :Treated cells with purified toxin of K.Pneumoniae K8, showing vacuoles, necrotized cells, due to the effects of toxin.
Figure (6): Monolayer cells treated with Purified toxin of $K$. Pneumoniae K8.

The biological effects of purified toxin on the morphology of rat embryo fibroblast cell was very clear in comparison with the control as in figure (2). In control wells the rat embryo fibroblast cells were spindle in shape, but when inoculated with purified toxin $K$.pneumoniae $\mathrm{K} 8$ for 72 hours (exposure time ) the cells became irregular and many vacuoles were seen inside the cytoplasm .

Raetz .,et al [16] proposed models for endotoxin activating cells as in figure (7). That the LPS binds to a LPS binding protein ( LBP) forming a complex which interacts with a membrane anchored CD14 receptor. This results in the generation of an intracellular signal that turns on cytokine production ( TNF and Interleukins ) at stability. Risco., et al.,[17] demonstrated that LPS may also interact with cells by other means, since some cells lacking CD14 receptors have been shown to be affected by LPS. LPS may enter the cell by unknown receptors, endocytosis, or by directly entering the cell membrane or could bind to cytoskeleton microtubules, and at high concentrations inhibit microtubule polymerization. This binding could explain one possible mechanism for some of the cytotoxic effects of LPS that do not appear to involve cytokine activation. 


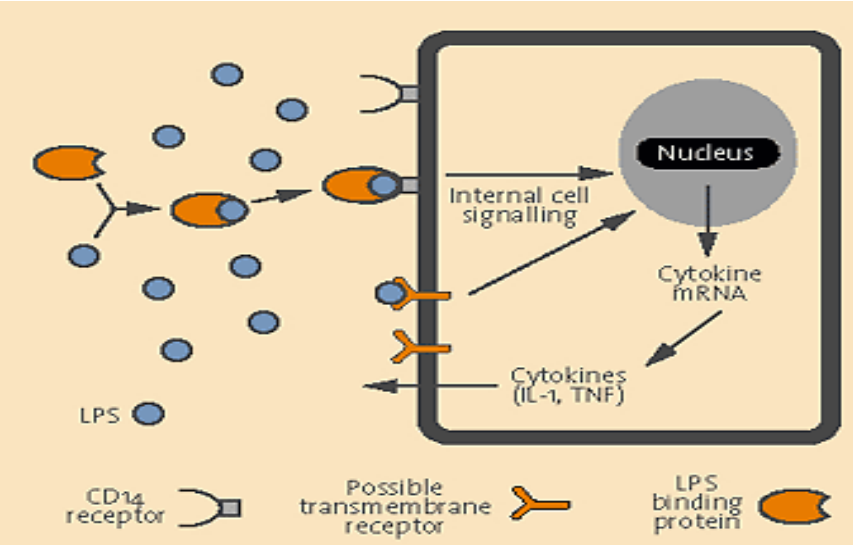

Figure (7): One of the proposed models for endotoxin activating cells.[16].

Sometimes morphological changes are reversible upon exposure to clean media also, the effects upon morphology may vary with different endotoxins.

Estimation of cytotoxic concentration of purified toxin of K.pneumoniae K8 on REF-11 cells by ( ELISA )

Rat embryo fibroblast cells were seeded in 96- well plate at a density of $3 \times 10^{3}$ cells $/ \mathrm{ml}$ in each well to determine cytotoxicity after 72 hours exposure to purified toxin of K.pneumoniae $\mathrm{K} 8$ which was purified on DEAE-cellulose column which gave three peaks from ETC protein [18], in serum-free culture medium, and also recorded the 50\% cytotoxicity concentration in each well and the growth inhibition of cells according to the concentration of toxin which was added to each wells. the result was investigated by monitoring the 96-well plate in ELISA at $492 \mathrm{~nm}$ using crystal violet staining .

From table ( 1) the result of cytotoxic concentration was $51 \%$ in the well which belong to toxin that obtained from Peak-I in purification of toxin by DEAE-cellulose column [18 ].

All 96 - well plate showed toxicity, except the wells of the control. It means that the toxin in peak-I was more toxic than in other peaks.It also means that the concentration of toxic materials in peak-I was higher than in the others.

Table ( 1 ) : Estimating of cytotoxic concentration of purified toxin of $K$. pneumonia K8 by ELISA

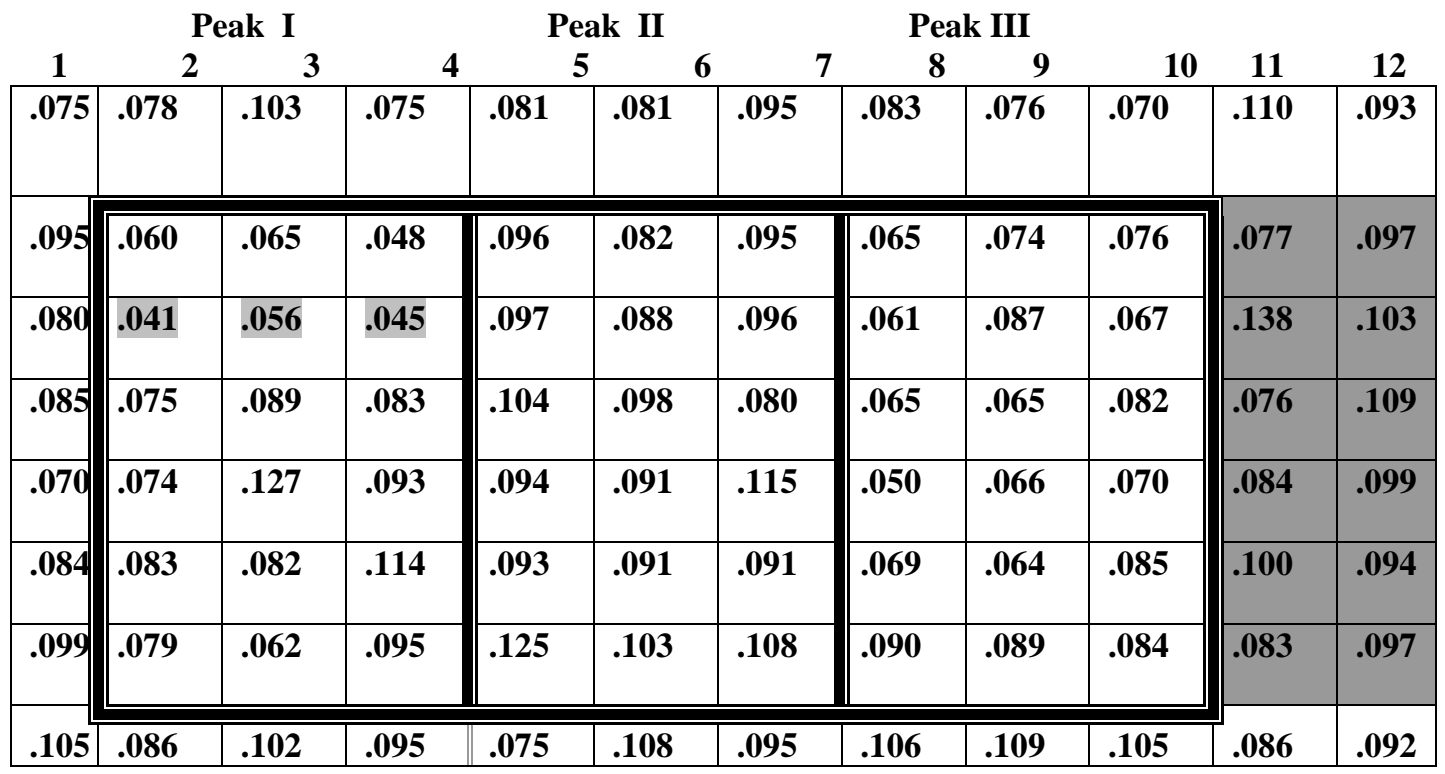

Control well

Then the cytotoxic concentration was calculated as:

$\mathrm{C} \mathrm{C \%}=$ Treatment value-Control value /Control X 100. 


\section{REFERENCES}

1). Bartlett, J. G.; O'Keefe, P; Tally,F.P; Louie,T.J and Gorbach, S.L. (1986).Bacteriology of hospitalacquired pneumonia. Arch. Intern. Med. 146:868-871.

2). Knirel, Y.A.; Kocharova, N.A.; Bystrova, O.V.; Katzenellenbogen, E. and Gamian, A. (2002).Structures and serology of the O-specific polysaccharides of bacteria of the genus Citrobacter. Arch. Immunol. Ther. Exp. $50:$ 379-391.

3). Frridge, C.; Bennett-Guerrero, E. and Poxton, I.R. (2002).Structure and function of lipopolysaccharides. Microbes Infect. $4: 837-851$.

4). Cavaillon, J.M.; Fitting ,C. ; Caroff, M. and Haeffner-Cavaillon, N.(1989). Dissociation of cellassociated interleukin-1 (IL-1) and IL-1 release induced by lipopolysaccharide and lipid A. Infect. Immun. 57(3):791-797.

5). Loppnow, H.; Brade, H.; Durrbaum, I.; Dinarello, C.A.; Kusumoto, S; Rietschel, E.T. and Flad, H.D. (1989). IL-1 inductioncapacity of defined lipopolysaccharide partial structures. J.Immunol. 142:32293238.

6). Mannel, D. N. and Falk,W. (1989). Optimal induction of tumor necrosis factor production in human monocytes requires complete S-form lipopolysaccharide. Infect. Immun. 57:1953-1958.

7). Parent, J. B. (1990). Membrane receptor on rat hepatocytes for the inner core region of bacterial lipopolysaccharides. J. Biol.Chem. 256:3455-3461.

8). Laichalk, L.L; Kunkel, S.L; Strieter, R.M; Bailie, M.B. and Standiford, T.J .(1996).Tumor necrosis factor mediates lung antibacterial host defense in murine Klebsiella pneumonia .Infect.immun. 64:52115218.

9). Straus, D. C. (1987). Production of an extracellular toxic complex by various strains of Klebsiella pneumoniae. Infect. Immun. 55:44-48.

10). Straus, D. C.; Atkisson, D.L and Garner, C.W. (1985). Importance of lipopolysaccharide-containing extracellular toxic complex in infections produced by Klebsiella pneumoniae. Infect. Immun. 50:787795 .

11). Williams, P. and Tomas, J. M. (1990). The pathogenicity of Klebsiella pneumoniae. Rev Med Microbiol. 1:196-204.

12). Mohammed, M.S. ( 2007). Biological effects of Klebsiella pneumoniae toxin in albino mice (in vivo \& in vitro). Ph.D thesis . College of Education -Ibn Al-Haitham. Baghdad University . Baghdad, Iraq.

13). Cavaillon, J.M.; Fitting ,C. ; Caroff, M. and Haeffner-Cavaillon, N.(1989). Dissociation of cellassociated interleukin-1 (IL-1) and IL-1 release induced by lipopolysaccharide and lipid A. Infect. Immun. 57(3):791-797.

14). Freshney, R.I. (2000). Culture of animal cells: A manual for basic technique $\left(4^{\text {th }}\right.$ ed.). Wiley-liss, A John wiley and sons, Inc. publication, New York.

15). Thompson, L.U.; Seid, M.M.; Rickard, S.I.; Orcheson, L. and Fong, H.H.S. (1996). Antitumorigenic effect of a rnammalian lignan precursor from flaxseed. Nutr. Cancer. 26: 159-165.

16). Raetz,C.R; Ulevitch, R.J; Wright, S.D; Sibley, C.H; Ding, A and Nathan, C.F. (1991). Gram-negative Endotoxin: An Extraordinary Lipid with Profound Effects on Eukaryotic Signal Transduction. FASEB J. 5:2652-2660.

17). Risco, C.; Dominguez, J. E. Bosch, M. A. and Carrascosa, J. L. (1993). Biochemical and Electron Microscopy Analysis of the Endotoxin Binding to Microtubules in vitro. Mol. Cell. Biochem. 121:6774.

18). Al-Jumaily,E.F.; Mohammed S. M., and Yaseen, N.Y (2012). Purification of Extracellular Toxic Complex ( ETC ) for local strain Klebsiella pneumoniae K8. Trend Life Science. 1:2 . 